OPEN ACCESS

Edited by:

François G. Schmitt, UMR8187 Laboratoire d'Océanologie et de Géosciences (LOG), France

Reviewed by:

Raghab Ray,

University of Tokyo, Japan

José Pinho,

University of Minho, Portugal

*Correspondence:

Sabine Schmidt

sabine.schmidt@u-bordeaux.fr

Specialty section: This article was submitted to Coastal Ocean Processes,

a section of the journal Frontiers in Marine Science

Received: 06 February 2019 Accepted: 07 June 2019

Published: 21 June 2019

Citation:

Schmidt S, Diallo II, Derriennic H,

Fallou H and Lepage M (2019)

Exploring the Susceptibility of Turbid

Estuaries to Hypoxia as a Prerequisite to Designing a Pertinent Monitoring

Strategy of Dissolved Oxygen.

Front. Mar. Sci. 6:352.

doi: 10.3389/fmars.2019.00352

\section{Exploring the Susceptibility of Turbid Estuaries to Hypoxia as a Prerequisite to Designing a Pertinent Monitoring Strategy of Dissolved Oxygen}

\author{
Sabine Schmidt ${ }^{1 *}$, Iris I. Diallo ${ }^{1,2}$, Hervé Derriennic ${ }^{1}$, Hélène Fallou ${ }^{3}$ and Mario Lepage ${ }^{4}$ \\ 1 UMR5805 EPOC, CNRS, OASU, Université de Bordeaux, Pessac, France, ${ }^{2}$ Rectorat de Bordeaux, Bordeaux, France, \\ ${ }^{3}$ GIP Loire Estuaire, Nantes, France, ${ }^{4}$ IRSTEA, UR EABX, Cestas, France
}

Globally, there has been a decrease in dissolved oxygen in the oceans, that is more pronounced in coastal waters, resulting in more frequent hypoxia exposure for many marine animals. Managing hypoxia requires an understanding of the dynamics of dissolved oxygen (DO) where it occurs. The French coast facing the Bay of Biscay ( $N$ E Atlantic Ocean) hosts at least a dozen tidal and turbid estuaries, but only the large estuaries of the Gironde and the Loire, are subject to a continuous monitoring. Here, we compared the DO dynamics in these two systems, in order to evaluate to what extent it is possible to predict the sensitivity to hypoxia of a tidal and turbid estuary based on its most common and easily accessible characteristics (the estuary surface area and length, liquid and solid discharge, suspended particulate load, water renewal time, presence of cities). Whereas the hyperturbid Gironde estuary is the longest (170 km), implying longer water and particle residence times, and is bordered by a large metropole $(>750,000$ inhabitants), only episodic summer hypoxia events ( $\mathrm{DO}<2 \mathrm{mg} \mathrm{L}^{-1}$ ) were recorded in its urban Garonne subestuary. In contrast, the turbid Loire estuary, smaller in terms of surface area and length, experiences permanent summer hypoxia. This demonstrates the inability to evaluate the susceptibility of a tidal and turbid estuary to hypoxia only by considering its general characteristics. We urge that there is a need for a pertinent DO survey strategy based on an initial assessment of DO in a specific estuary based on longitudinal investigations, in particular during the warm season (as higher water temperatures decrease DO solubility), for detecting the potential zones of minimum DO.

Keywords: estuary, Loire, Gironde, dissolved oxygen, hypoxia, turbidity, monitoring

\section{INTRODUCTION}

The French Atlantic coast hosts numerous macrotidal estuaries that flow into the Bay of Biscay that are natural corridors for migratory fishes (Figure 1A). The two best known are those of the Gironde and the Loire, which are also the longest, at $180 \mathrm{~km}$ (considering the Gironde-Garonne system) and $100 \mathrm{~km}$, respectively. However, there are also a dozen estuaries set geographically among them, of a smaller scale, such as those of the Charente $(82 \mathrm{~km})$, 


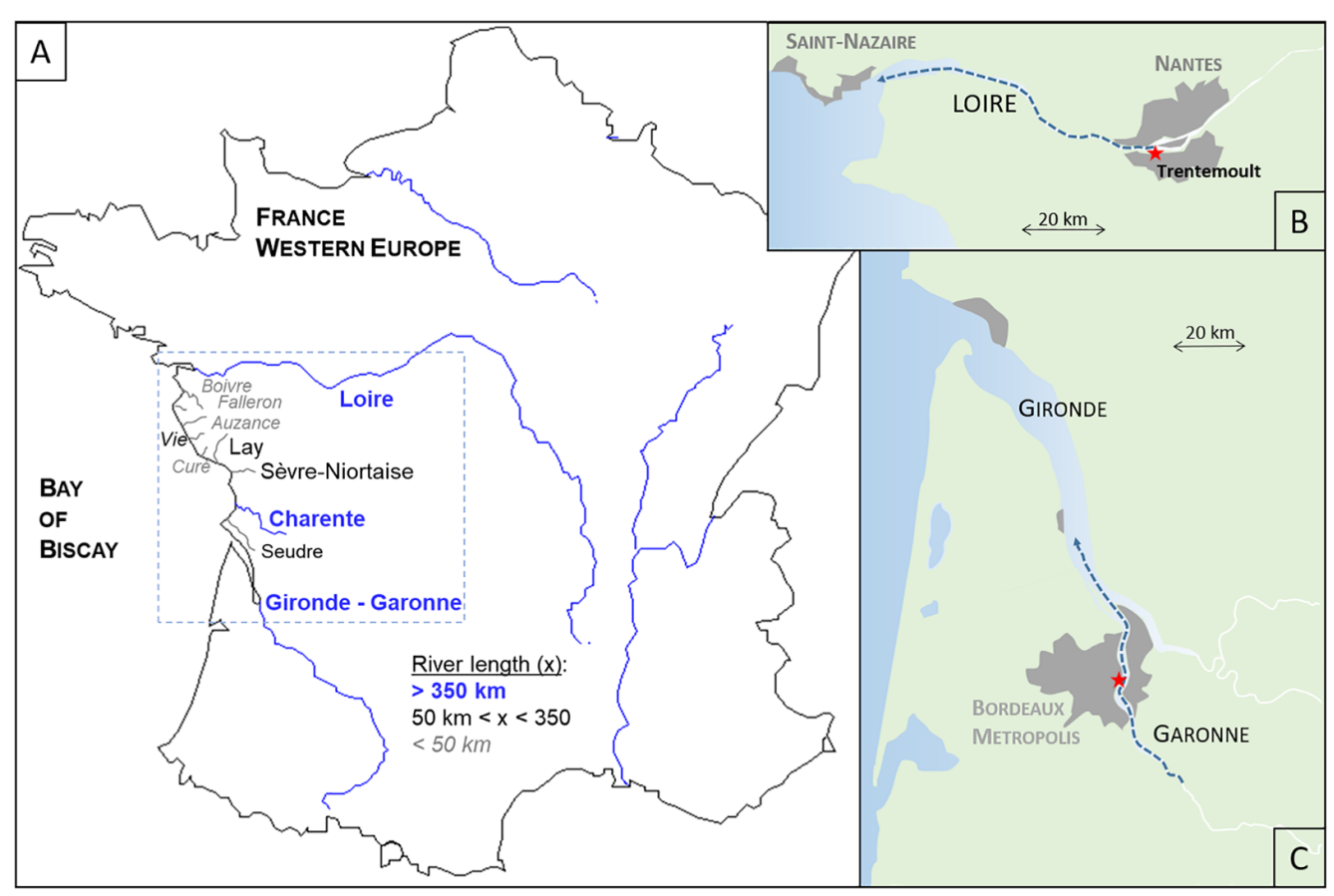

FIGURE 1 | (A) Estuaries facing the Bay of Biscay between the Loire and the Gironde. (B) The Loire estuary. (C) The Gironde estuary. Gray areas indicate the main cities. The range of the total river length $(x)$ is given (the extension of the tidal section is not always defined for the small estuaries).

the Seudre $(23 \mathrm{~km})$ or the Auzance $(5 \mathrm{~km})$. The asymmetry of the tidal wave, when propagating upstream, creates a welldeveloped turbidity maximum zone (TMZ), with concentrations of suspended particulate matter (SPM) of several hundred milligrams of dry sediments per liter (Toublanc et al., 2016). This TMZ is defined as an estuarine region where SPM concentrations exceed $0.5 \mathrm{~g} \mathrm{~L}^{-1}$ in the Loire or $1 \mathrm{~g} \mathrm{~L}^{-1}$ in the Gironde (Jalón-Rojas et al., 2015, 2017).

Extremely high SPM loads in transitional waters result in serious problems. In addition to silting, TMZ directly affects the water quality, in particular the oxygenation. First, the turbidity reduces the sources of dissolved oxygen (DO): it limits light penetration and thus photosynthetic activity (Kromkamp and Peene, 1995), and gas exchange with the atmosphere (Lanoux et al., 2013). In addition, the degradation of the organic content of the SPM consumes DO. This specific feature is likely to promote a chronic undersaturation of dissolved oxygen in turbid estuarine waters, with respect to the expected value in equilibrium with the atmosphere at a given water temperature and salinity (Benson and Krause, 1984). Severe depletion of dissolved oxygen down to borderline concentrations close to hypoxia $\left(<2 \mathrm{mg} \mathrm{L}^{-1}\right)$ is a major threat for most aquatic organisms (Diaz and Rosenberg, 2008; Rabalais et al., 2010). In estuarine waters, critical thresholds are even higher: here, we use a threshold of below $3 \mathrm{mg} \mathrm{L}^{-1}$ for hypoxia and between 3 and $5 \mathrm{mg} \mathrm{L}^{-1}$ for critical DO inducing stress for most organisms (Curran and Henderson, 1988). Delage et al. (2019) showed that oxygen depletion induces sublethal effects at $70 \% \mathrm{O}_{2}$ saturation and lethal effects at $50 \% \mathrm{O}_{2}$ saturation during the early life phases of the European sturgeon
Acipenser sturio. A minimum DO concentration of $5 \mathrm{mg} \mathrm{L}^{-1}$ is required all year long to preserve all resident and migratory fish species, including the most sensitive (Breitburg, 2002). Spatial extension of the deoxygenated zone is also critical for fishes, in particular for migrating species (Alabaster and Gough, 1986; Woodland et al., 2009; Hrycik et al., 2017).

Dissolved oxygen is one of the key physico-chemical quality elements that must be considered under the EU Water Framework Directive (WFD) to reach a "good ecological status" of transitional waters (Best et al., 2007; Carvalho et al., 2019). Hypoxia is indeed not the only stressor that impacts coastal ecosystems, but it also co-occurs with other factors (toxic substances, overfishing, urbanization) to decrease the ecological well-being of coastal waters (Committee on Environment and Natural Resources, 2010). Future global changes are expected to have negative effects on water quality: a warmer climate, by decreasing oxygen solubility and increasing respiration, may counteract the impacts of reduced organic pollution loading (Bendtsen and Hansen, 2013; Trolle et al., 2019). Based on the projected increases in temperature for 2050 and 2100, a $3 \mathrm{D}$ model of dissolved oxygen highlighted a trend toward a development of a permanent summer hypoxia in the urban Garonne subestuary (Lajaunie-Salla et al., 2018). There is then a need to record reliable observations in order to better understand DO dynamics and thus to improve preventive or remediation management strategies for hypoxia in transitional waters and to counterbalance the expected DO decrease under climate (temperature increase, salinization) and local (water abstraction, urbanization, waste water discharges) pressures 
(Breitburg et al., 2018). However, there is a lack of systematic surveys in estuarine systems, and the small estuaries of a few $\mathrm{km}$ to $10 \mathrm{~km}$ are often neglected.

The objective of this work was to explore the possibility of assessing the susceptibility of tidal and turbid estuaries to hypoxia by considering their basic characteristics (estuary surface area and length, liquid and solid discharge, water renewal time). We have chosen as a case study the estuaries from the French Atlantic coast facing the Bay of Biscay. The strategy was to investigate the occurrence of hypoxia in the two best-known estuaries, the Gironde and Loire. The aim was to identify the potential prevailing conditions and to assess whether or not a survey of every estuary remains justified. First, we compared the main characteristics of the two systems likely to influence dissolved oxygen in order to forecast the oxygenation levels of their waters. Then, two different datasets (a long-term survey of the urban sector and longitudinal surveys) are presented in order to test the hypothesis. This study aimed to propose a strategy to test the hypoxic nature of an estuary as an indispensable prerequisite to further implementation of a DO survey.

\section{MATERIALS AND METHODS}

\section{Study Site}

The Gironde and Charente estuaries surround smaller-scale systems: from north to south the Boive, Falleron, Auzance, Vie, Curé, Lay, Sèvre-Niortaise, Charente, and Seudre (Figure 1). All of these estuaries that flow into the Bay undergo twice a day marine intrusion, with typical tidal ranges between 1.5 and $6 \mathrm{~m}$ at the mouth. Because of their macrotidal regime (tide height $>5 \mathrm{~m}$ ) and the nature of their drainage basin, these systems present a maximum turbidity zone. The regional climate is oceanic: temperate with a warm summer. The perturbations, coming mainly from the Atlantic Ocean, bring rains almost all year round, but the rainfall peaks in winter whereas a summer minimum persists most often. Accordingly, fluvial discharges present a marked seasonal signal with a low-water period in summer and autumn. There is always the presence of, at least, a city, which is expected in 2019 to have wastewater collection and treatment systems according to the EU rules. However, urban wastewater treatment plants (WWTP) have variable efficiencies in treating organic matter (dissolved and particulate) and ammonia and in restraining storm sewage overflows.

\section{High-Frequency Monitoring of Dissolved Oxygen}

The Gironde and Loire estuaries have programs of long-term, high-frequency and multisite monitoring of essential physicochemical variables, called MAGEST and SYVEL, respectively. These networks measure the temperature, salinity, turbidity, and dissolved oxygen in the surface waters every $10 \mathrm{~min}$. In 2004, the Gironde was the first to be equipped with a realtime measurement network; a detailed description is given in Etcheber et al. (2011). Four stations were constructed in the central and fluvial estuary, in particular in the urban Garonne subestuary in Bordeaux (Figure 1). Following this example, the
Loire estuary was also equipped with automated stations at the end of 2006 (Jalón-Rojas et al., 2017). The sensors were produced by Endress Hausser. The measuring range of the oxygen sensor (OXYMAX W COS41) was 0-20 $\mathrm{mg} \mathrm{L}^{-1}\left( \pm 0.2 \mathrm{mg} \mathrm{L}^{-1}\right.$; Etcheber et al., 2011). The automated stations were found to be rather expensive to operate and were replaced in $2017-2018$ by a new generation of autonomous multiparameter probes, called SAMBAT, developed by NKE Instrumentation (France). The measured parameters are temperature $\left(-5\right.$ to $\left.+35^{\circ} \mathrm{C} ; \pm<1 \%\right)$, salinity (range $0.1-42 ; \pm<5 \%$ ), turbidity (0-3000 NTU; $\pm<5 \%$ ), dissolved oxygen $\left(0-20 \mathrm{mg} \mathrm{L}^{-1} ; \pm 0.1 \mathrm{mg} \mathrm{L}^{-1}\right)$ and fluorescence (0-50 $\left.\mu \mathrm{g} \mathrm{L}^{-1} ; \pm<5 \%\right)$. Data are transmitted daily to the dedicated data servers. This allows for a real time survey of water quality and of critical DO levels. It also permits the detection of potential problems (sensor drift) in addition to the normal required 3-month maintenance. The data are freely available on-demand ${ }^{1,2}$.

\section{Longitudinal Surveys of DO Distribution}

Fixed stations are very important for recording long-term observations with a high temporal resolution, but they cannot document the spatial extension of deoxygenation. Indeed, there are usually few instrumented locations and a low spatial resolution in a given system, as it is not possible to dramatically increase the number of stations due to the human and material costs. In this work, we applied a complementary strategy based on longitudinal surveys along the estuarine axis that we believe is the only way to determine the spatial extension of deoxygenation. In 2017 and 2018, field campaigns were realized in the Gironde and Loire estuaries. The transects were scheduled in order to begin the measurements at high tide from a site located upstream of an area where severe deoxygenation had already been reported. Then, we moved at a low speed downstream with a SAMBAT, maintained at $0.5 \mathrm{~m}$ below the surface, that collected a measurement every $2 \mathrm{~min}$. The transects in the Gironde (Loire) estuary correspond to 172 (118) and 197 (90) measurements in 2017 and 2018, respectively. The boat was regularly stopped to send an optode (0-20 mg L ${ }^{-1} ; \pm 0.1 \mathrm{mg} \mathrm{L}^{-1}$, SDOT, NKE Instrumentation) underwater in order to establish a vertical DO profile from the surface waters to the bottom. Simultaneously, water samples were collected to determine the SPM concentration (by filtering a known volume of water on a precombusted and preweighted GFF filter, error $\pm 2 \mathrm{mg} \mathrm{L}^{-1}$ ) in order to estimate the turbidity/SPM rating curve. In 2018, the particulate organic carbon (POC) fraction was also determined by direct combustion of these filters in an LECO CS 125 analyzer (error <3\%). The data are available on an open-access repository (Schmidt, 2019).

\section{RESULTS}

\section{Trend of DO in the Urban Sections}

The estuaries of the Loire and the Gironde are characterized by the presence of a metropolis in their upstream reaches:

\footnotetext{
${ }^{1} \mathrm{http}: / /$ www.loire-estuaire.org/dif/do/network

${ }^{2}$ http://rogir.epoc.u-bordeaux1.fr/Ayant_Droits/donnees/
} 
Nantes and Bordeaux, respectively (Figure 1). Hypoxia is often reported in the vicinities of such large cities, due to the input of organic matter and nutrients from wastewater discharges (Garnier et al., 2001; Zhang et al., 2015). The multiyear continuous record of dissolved oxygen in Nantes (Trentemoult site) and Bordeaux presents the same multiscale variability (Figure 2). First, the tide explains the short-term oscillations during the semidiurnal and fortnightly timescales. The high currents at mid-tide, particularly during spring tides, enhance resuspension of particulate organic matter, which becomes available to heterotrophic bacteria and then promotes oxygen consumption (Schmidt et al., 2017). However, the largest variability is clearly related to season. As the low salinity in both sites, typically below 2 , is not expected to significantly influence oxygen solubility, the main controlling factors must be temperature, fluvial discharge or turbidity. The mean DO concentrations a 9.4 and $7.8 \mathrm{mg} \mathrm{L}^{-1}$ in the Nantes and Bordeaux surface waters, respectively. Half of the DO data in Nantes are rather high, from 8.0 to $10.9 \mathrm{mg} \mathrm{L}^{-1}$, compared to that recorded in Bordeaux (5.8 to $9.7 \mathrm{mg} \mathrm{L}^{-1}$ ). The lowest DO concentration $\left(0.74 \mathrm{mg} \mathrm{L}^{-1}\right)$ was measured in Nantes (1.22 was the lowest in Bordeaux). In addition, it is noticeable that the Nantes surface waters experienced hypoxia events almost every year. Although the DO range is lower in Bordeaux, a single

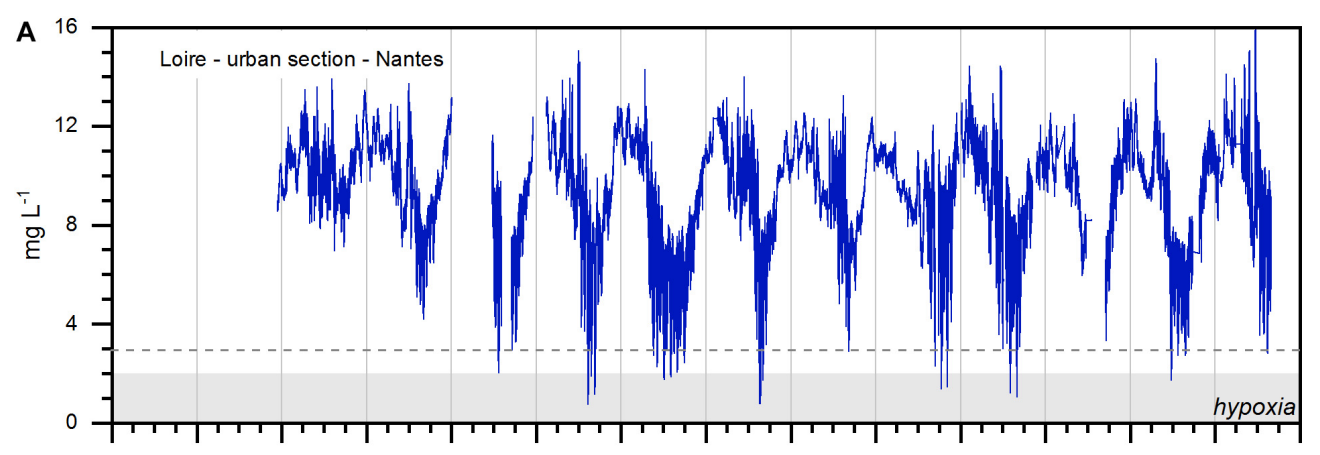

B

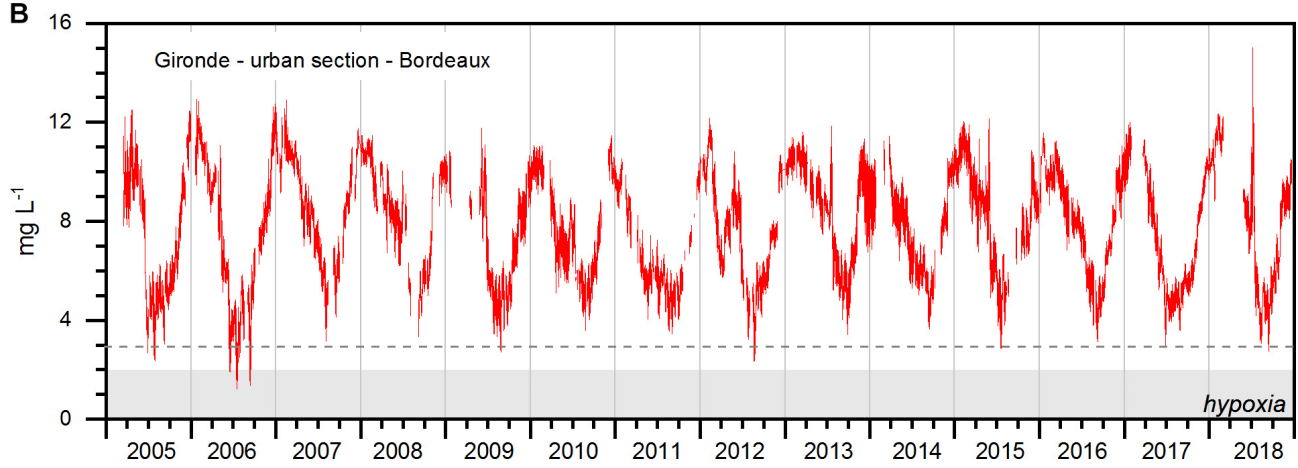

FIGURE 2 | Comparison of high-frequency DO records in the urban section of the Loire (A; 452,433 measurements) and Gironde (B; 506,167 measurements) estuaries. Gray areas underline DO concentrations corresponding to hypoxia stricto sensus.
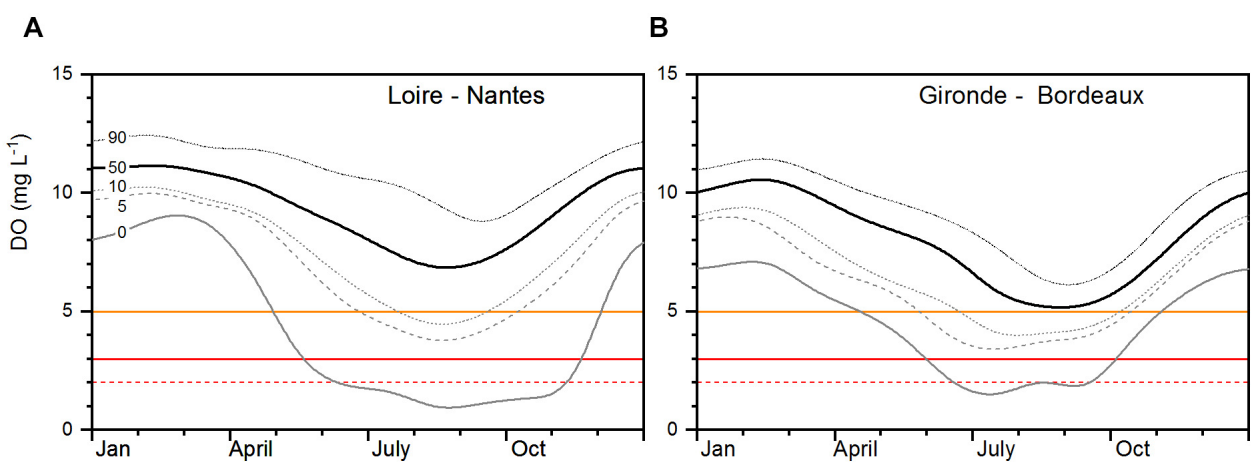

FIGURE 3 | Monthly distribution of percentiles values of DO (0, 5, 10, 50 and 90 percentiles) in the urban section of the panel (A) Loire (Nantes) and panel (B) Gironde (Bordeaux) estuaries. The horizontal lines correspond to the values of 2 (the commonly used threshold for hypoxia), 3 and 5 mg $L^{-1}$. Values between 3 and 5 induce stress for most organisms. 

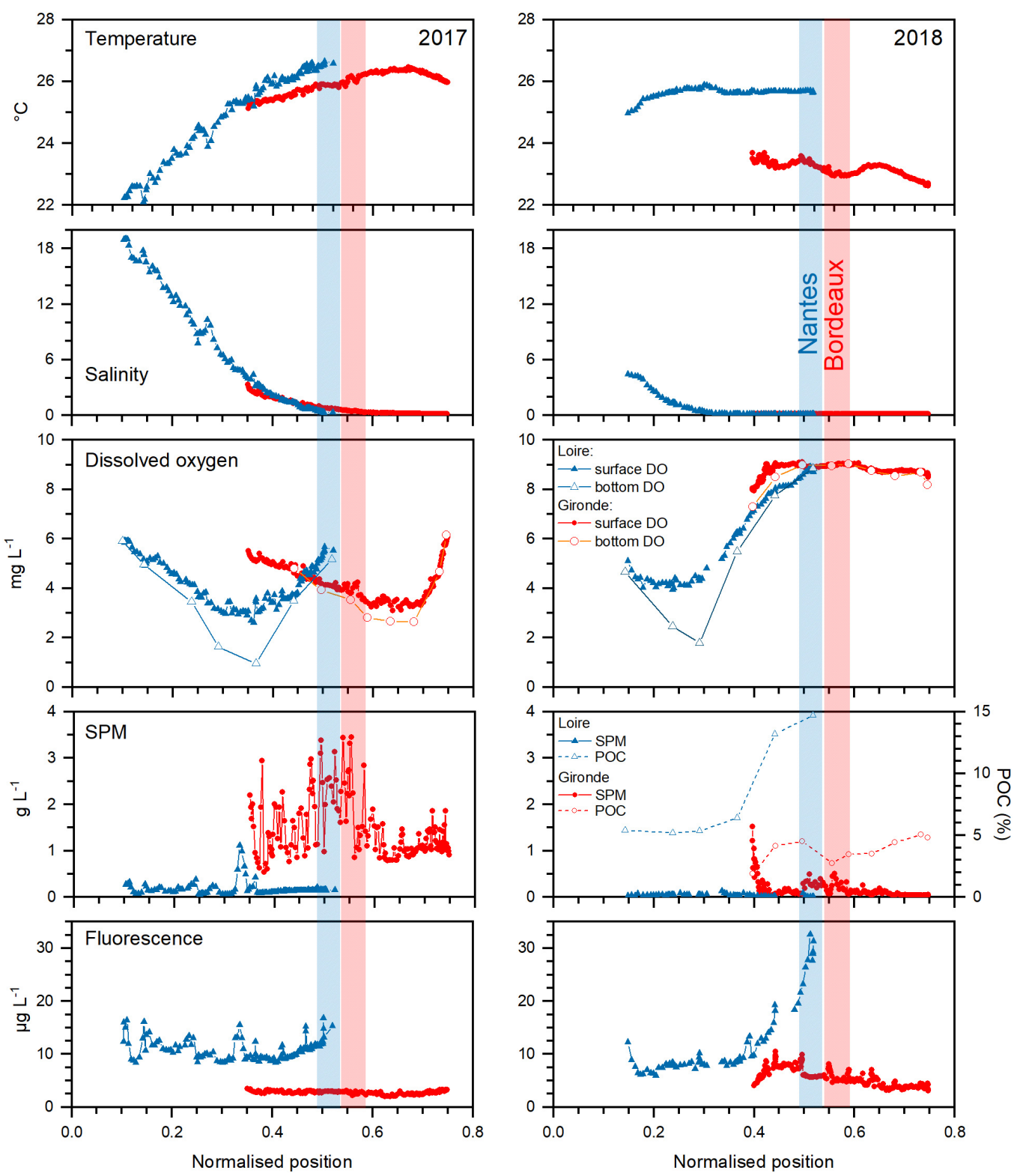

FIGURE 4 | Longitudinal surveys of dissolved oxygen and ancillary data (temperature, salinity, suspended particulate matter, fluorescence) in the Loire and Gironde estuaries in 2017 and 2018. POC content of SPM was determined only in 2018 ( 9 and 6 samples collected in the Gironde and Loire estuary, respectively). The distance from the mouth is normalized by the total length of the corresponding estuary. The measurement dates were the June 21, 2017 and July 5, 2018 in the Loire estuary; the June 27, 2017 and June 28, 2018 in the Gironde estuary.

hypoxia event was recorded during the summer of 2006 for the period 2005-2018.

This trend is more obvious when considering the monthly mean (Figure 3). In Bordeaux, DO median concentrations are only slightly above the threshold of $5 \mathrm{mg} \mathrm{L}^{-1}$ in August and September. Nevertheless, at present, hypoxia events are still rare (Figure 3). In Nantes, the median DO is always above $6.7 \mathrm{mg} \mathrm{L}^{-1}$, whatever the season. This might be seen as a conformable safety margin compared to Bordeaux. However, hypoxic DO concentrations were measured over a large temporal window, from May to November.

\section{Longitudinal Surveys}

The longitudinal surveys established in 2017 and 2018 correspond to highly contrasted situations. In 2017, it was conducted at the end of a heat wave and a dry first semester (mean fluvial discharge for the period from January to June: 596 and $493 \mathrm{~m}^{3} \mathrm{~s}^{-1}$ for the Loire and the Gironde-Garonne, respectively). In 2018, the first half-year was particularly wet (1467 and $\left.1173 \mathrm{~m}^{3} \mathrm{~s}^{-1}\right)$. This explains the large difference in salinity between the 2 years, especially for the Loire, as the transect ended almost at the mouth (Figure 4). The TMZ occurrence was also highly contrasted between the 2 years: 
during dry conditions (2017), the presence of the TMZ was very marked in the Gironde but to a lesser extent in the Loire. In 2018, the TMZ was nearly absent from the Loire and only recorded at the end of the transect in the Gironde. Fluorescence, used as a rough tracer of chlorophyll in turbid waters, was always higher in Loire waters and decreased with increasing SPM. Both the Gironde and Loire transects intercept the urban section. Nevertheless, it is clear that the minimal values along each transect are found elsewhere: systematically, approximately $20 \mathrm{~km}$ downstream from Nantes. For the Gironde-Garonne transect, it is much more variable: in 2017, the DO minimum was upstream from Bordeaux and associated with the highest temperature, and in 2018 it was downstream from the metropolis in the TMZ. The lowest surface DOs were always recorded in the Loire estuary. In addition, whereas the bottom and surface DO were rather comparable in the Gironde, the bottom Loire waters were clearly hypoxic in the deoxygenated zone.

\section{DISCUSSION}

\section{Assumptions for Predicting Hypoxia Susceptibility in a Tidal Estuary}

Several estuaries facing the Bay of Biscay are located between the Loire and the Gironde ones. Only these two large systems are instrumented for DO surveys and can provide the possibility of comparing theoretical and in situ assessments. The first objective of this work was to evaluate to what extent it is possible to predict the susceptibility of a tidal estuary to hypoxia. The theoretical evaluation relies on the comparison of the openaccess and common characteristics that are likely to influence oxygenation in a tidal estuary, besides turbidity (Table 1). The main forcing factors of DO dynamics in the Gironde estuary are temperature, fluvial discharge, particulate load and to a lesser extent tidal cycles and urban input (WWTP inputs, referring to metropolis inhabitants) (Schmidt et al., 2017). We did not consider parameters such as excess nitrification, biological oxygen demand or organic matter and nutrient fluxes from the drainage basin, as this information is usually not available for small estuaries.

At the difference of Mediterranean-type estuaries, macrotidal systems, i.e., those with a tidal range $>5 \mathrm{~m}$, are well flushed and vertically partially or fully mixed, preventing a priori stratification (Xing et al., 2013; Warwick et al., 2018). The surface and length of an estuary compared to the fluvial discharge determine the flushing efficiency and thus the water residence time, increases of which are adverse for dissolved oxygen. Supplies of organic matter and nutrients from the watershed and the cities are expected to increase with the size of the watershed surface area and the city population. Table 1 summarizes the main characteristics and their impact on DO, and highlights the most unfavorable case between the Loire and Gironde estuaries. The high residence times of water and of particles in the Gironde estuary are not favorable features for DO. Bordeaux is also a more populous metropolis compared to Nantes (Table 1; $+23 \%$ in 2014). On the other hand, the Loire estuary is the receptacle of a larger watershed. The comparison of their different characteristics tends to describe the Gironde estuary as a site more exposed to hypoxia risk.

\section{Hypoxia Occurrences in the Loire and Gironde Estuaries}

The prediction based on their respective features was not confirmed by the DO dataset, whether this is assessed based on the long-term regional monitoring or the specific longitudinal surveys in 2017/2018. Over the past 15 years, the urban sections of the two considered estuaries have registered hypoxia events, though less frequently in the urban Garonne subestuary (Figure 3). In addition, the longitudinal surveys clearly demonstrate the presence of a permanent summer deoxygenation to levels below the hypoxia threshold downstream of Nantes. Along the Gironde estuary, the position of the low oxygen zone is more variable, and it can be up- or downstream of Bordeaux, depending on the fluvial discharge and the climatic conditions over the last few months. The localization of a large city (urban runoffs, WWTP discharges) does not appear to be one of the main criteria to locate the DO minimum along the estuarine axis.

Although the two estuaries are close spatially, there are differences in their DO dynamics. Table 2 summarizes the Pearson's correlation coefficients between daily averaged DO and various parameters (temperature, discharge, turbidity). There are notable differences for the same site for the correlation coefficients depending on the considered period (whole year or low-DO season) and among sites for a given period. On an annual

TABLE 1 | Comparison of estuarine characteristics likely to influence positively $(\nearrow)$ or negatively $(\searrow$ ) water oxygenation when increasing.

\begin{tabular}{|c|c|c|c|c|}
\hline & $\begin{array}{l}\text { Impact } \\
\text { on DO }\end{array}$ & & LOIRE & GIRONDE \\
\hline Tidal range & $\nearrow$ & $\mathrm{m}$ & 6.36 & 6.3 \\
\hline Watershed surface area & 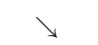 & $\mathrm{km}^{2}$ & $\underline{117.5}$ & 81 \\
\hline Estuary surface area & $\checkmark$ & $\mathrm{km}^{2}$ & 102 & $\underline{635}$ \\
\hline Length & & $\mathrm{km}$ & 100 & $\underline{180}$ \\
\hline Mean annual liquid discharge & 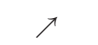 & $m^{3} s^{-1}$ & 860 & $\underline{680}$ \\
\hline Water renewal time in summer & & Day & 20 & $\geq 100$ \\
\hline Mean annual solid discharge & & $10^{6}$ ton year $^{-1}$ & $0.2-2$ & $\underline{1.5-3}$ \\
\hline Estuarine SPM stock & & $10^{6}$ ton & 1 & 5 \\
\hline Metropolis inhabitants (2014) & 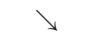 & $\mathrm{nb}$ & 603,000 & $\underline{760,933}$ \\
\hline
\end{tabular}

Underlined values highlight the most unfavorable case between the Loire and the Gironde estuaries.

TABLE 2 | Pearson's correlation coefficients between daily average DO (mg L $\left.{ }^{-1}\right)$ and parameters, i.e., temperature, discharge and turbidity for the complete time-series (all seasons) and for the period from May to October.

\begin{tabular}{lcccc}
\hline $\begin{array}{l}\text { Do } \\
\left(\mathbf{m g ~ L} \mathbf{~}^{-\mathbf{1}}\right)\end{array}$ & $\begin{array}{c}\text { Temperature } \\
\mathbf{(} \mathbf{C} \mathbf{C})\end{array}$ & $\begin{array}{c}\text { Discharge } \\
\left(\mathbf{m}^{\mathbf{3}} \mathbf{s}^{-\mathbf{1}} \mathbf{)}\right.\end{array}$ & $\begin{array}{c}\text { SPM } \\
\mathbf{( \mathbf { g ~ L ~ } ^ { - 1 } )}\end{array}$ \\
\hline Gironde & Bordeaux & & & \\
All seasons & 3578 & -0.85 & 0.54 & -0.38 \\
May-October & 1916 & -0.55 & 0.60 & -0.25 \\
Loire & Nantes & & & \\
All seasons & 3445 & -0.67 & 0.47 & -0.63 \\
May-October & 1716 & -0.20 & 0.35 & -0.63
\end{tabular}


basis, temperature is the main controlling factor of DO variability $(-0.85)$ in Bordeaux waters, far beyond turbidity and discharge. In the case of the Loire, at Nantes, turbidity is equivalent to temperature. The differences are even larger when considering only the periods during which low DOs have been measured (Figure 4); indeed, in the case of the Atlantic estuaries, the only common factor is the absence of a low DO during winter and early spring. From May to November, there is an obvious decoupling between the two estuaries. Whereas discharge and temperature have their main impact in the Gironde, SPM is the predominant controlling factor of deoxygenation in Nantes (-0.63). This was not expected considering the huge concentration, higher level up to $1 \mathrm{~g} \mathrm{~L}^{-1}$, and extension, of several tens of $\mathrm{km}$, of the TMZ in the Gironde, that limits exchanges with the atmosphere. One explanation could be the POC content of SPM. In the TMZ core, POC is on average $1.5 \%$, with no seasonal variation, and 3.3\% in the Gironde and Loire estuaries, respectively (Etcheber et al., 2007). In 2018, the wet conditions permitted flushing the TMZ toward the mouth, and surface SPMs had a POC content ranging between 5 and 1.9\% in the Gironde and 15 and 5.2\% in the Loire (Figure 4). In the Loire, phytoplankton, a source of extremely labile organic matter, could contribute up to $50 \%$ of the total POC load due to eutrophication (Etcheber et al., 2007). This is corroborated by the higher fluorescence content recorded during longitudinal surveys in the Loire. In the Gironde, the lowest POC of the 2018 longitudinal survey was associated with the TMZ presence (Figure 4), and in fact, the high turbidity of the waters prevents primary production during most of year and then limits the production of labile SPM, demonstrated by the low fluorescence concentration (Irigoiena and Castel, 1997). This accounts for the differences in the two estuaries: the higher organic content of the particles enhances oxygen consumption in the Loire estuary. Following the categories defined by Kemp et al. (2009), presentday hypoxia can be defined, depending on their occurrence; as persistent seasonal in the Loire estuary driven by a moderate TMZ during the warm season that does not impede primary production and subsequent organic matter degradation, and episodic in the Gironde estuary during peculiar hydrological and climatic conditions (i.e., droughts, heat waves).

\section{CONCLUSION}

Dissolved oxygen is one of the physicochemical quality elements that need to be considered to define the "good ecological status, according to the EU rules." The comparison of the Gironde and Loire estuaries demonstrates the difficulty in extrapolating the water quality of transitional waters only by considering basic and easily accessible characteristics. It is not possible to overcome

\section{REFERENCES}

Alabaster, J. S., and Gough, P. J. (1986). The dissolved oxygen and temperature requirements of Atlantic salmon, Salmo salar L., in the Thames Estuary. J. Fish Biol. 29, 613-621. doi: 10.1111/j.1095-8649.1986.tb04977.x preliminary acquisitions of DO concentrations of a tidal estuary to assess its susceptibility to hypoxia. The resulting question is then how to design a monitoring network, and in particular how to select the best sites to monitor. Our recommendations are to define first the local DO dynamics in relation to, at least, the discharge and SPM load over 2-3 years to investigate different hydrological contexts. In the case of the Atlantic estuaries facing the Bay of Biscay, the most critical period is the warm season, and the effort can then be concentrated on July to August. In the absence of historical DO data, it is necessary to conduct longitudinal surveys over the total estuarine length, and to establish evenly spaced depth profiles. The minimum parameters to determine are DO, temperature, salinity, SPM, and if possible, the fluorescence and organic content of particles. This investigation can help to define the zones of minimum DO. From there, it is possible to define the best sites to instrument for longterm surveys. When the MAGEST network was developed in 2004, the choice was made to monitor the city center, due to the presence of two WWTPs. The recent longitudinal surveys have revealed that there are in fact two intermittent low-DO zones, down- or upstream of Bordeaux, depending on the hydrology, justifying the future deployment of additional sites.

\section{AUTHOR CONTRIBUTIONS}

SS and ML conceived the research project. SS, ID, and ML collected field data during the longitudinal cruises. SS, ID, and HD operated the monitoring station at Bordeaux. SS analyzed the data and wrote the original draft. All co-authors commented on and approved the final manuscript.

\section{FUNDING}

This research was funded by the AFB, the French Office for Biodiversity (OFB) and by the OASU, (Aquitaine Observatory of the Sciences of the Universe). The authors warmly thank the long-term support of the Adour-Garonne water agency (AEAG) to the MAGEST monitoring network.

\section{ACKNOWLEDGMENTS}

The authors thank the MAGEST and SYVEL network for the temperature and dissolved oxygen time series, and Dominique Poirier (EPOC) for the carbon determination. The authors sincerely acknowledged Mickaël Vallée, one of the last professional fishermen of the Loire estuary, for the local cruise completion.

Bendtsen, J., and Hansen, J. L. S. (2013). Effects of global warming on hypoxia in the Baltic Sea-North Sea transition zone. Ecol. Modell. 264, 17-26. doi: 10.1016/j.ecolmodel.2012.06.018

Benson, B. B., and Krause, D. Jr. (1984). The concentration and isotopic fractionation of oxygen dissolved in freshwater and seawater in equilibrium 
with the atmosphere. Limnol. Oceanogr. 29, 620-632. doi: 10.4319/lo.1984.29. 3.0620

Best, M. A., Wither, A. W., and Coastes, S. (2007). Dissolved oxygen as a physicalchemical supporting element in the water framework directive. Mar. Pol. Bull. 55, 53-64. doi: 10.1016/j.marpolbul.2006.08.037

Breitburg, D. (2002). Effects of hypoxia, and the balance between hypoxia and enrichment, on coastal fishes and fisheries. Estuaries 25, 767-781. doi: 10.1007/ BF02804904

Breitburg, D., Levin, L. A., Oschlies, A., Grégoire, M., Chavez, F. P., Conley, D. J., et al. (2018). Declining oxygen in the global ocean and coastal waters. Science 359:eaam7240. doi: 10.1126/science.aam7240

Carvalho, L., Mackay, E. B., Cardoso, A. C., Battrup-Pedersen, A., Birk, S., and Blackstock, K. L. (2019). Protecting and restoring Europe's waters: an analysis of the future development needs of the water framework directive. Sci. Total Environ. 658, 1228-1238. doi: 10.1016/j.scitotenv.2018.12.255

Committee on Environment and Natural Resources (2010). Scientific Assessment of Hypoxia in U.S. Coastal Waters. Interagency Working Group on Harmful Algal Blooms, Hypoxia, and Human Health of the Joint Subcommittee on Ocean Science and Technology. Washington, DC: United States Environmental Protection Agency.

Curran, J. C., and Henderson, A. R. (1988). The oxygen requirements of a polluted estuary for the establishment of a migratory salmon, Salmo salar L., population. J. Fish Biol. 33(Suppl. A), 63-69. doi: 10.1111/j.1095-8649.1988.tb05559.x

Delage, N., Couturier, B., Jatteau, P., Larcher, T., Ledevin, M., Goubin, H., et al. (2019). Oxythermal window drastically constraints the survival and development of European sturgeon early life phases. Environ. Sci. Pollut. Res. Int. doi: 10.1007/s11356-018-4021-8 [Epub ahead of print].

Diaz, R., and Rosenberg, R. (2008). Spreading dead zones and consequences for marine ecosystems. Science 321, 926-929. doi: 10.1126/science.1156401

Etcheber, H., Schmidt, S., Sottolichio, A., Maneux, E., Chabaud, G., Escalier, J.-M., et al. (2011). Monitoring water quality in estuarine environments: lessons from the MAGEST monitoring program in the Gironde fluvial-estuarine system. Hydrol. Earth Syst. Sci. 15, 831-840. doi: 10.5194/hess-15-831-2011

Etcheber, H., Taillez, A., Abril, G., Garnier, J., Servais, P., Moatar, F., et al. (2007). Particulate organic carbon in the estuarine turbidity maxima of the gironde, loire and seine estuaries: origin and lability. Hydrobiology 588, 245-259. doi: 10.1007/s10750-007-0667-9

Garnier, J. P., Servais, G., Billen, M. A., and Brion, N. (2001). Lower seine river and estuary (France) carbon and oxygen budget during low flow. Estuaries 24, 964-976. doi: 10.2307/1353010

Hrycik, A. R., Almeida, L. Z., and Höök, T. O. (2017). Sub-lethal effects on fish provide insight into a biologically-relevant threshold of hypoxia. Oikos 126, 307-317. doi: 10.1111/oik.03678

Irigoiena, X., and Castel, J. (1997). Light limitation and distribution of chlorophyll pigments in a highly turbid estuary: the gironde (SW France). Estuar. Coast. Shelf Sci. 44, 507-517. doi: 10.1006/ecss.1996.0132

Jalón-Rojas, I., Schmidt, S., and Sottolichio, A. (2015). Turbidity in the fluvial gironde estuary (S.-W. France) based on 10-year continuous monitoring: sensitivity to hydrological conditions. Hydrol. Earth Syst. Sci. 19, 2805-2819. doi: 10.5194/hess-19-2805-2015

Jalón-Rojas, I., Schmidt, S., and Sottolichio, A. (2017). Comparison of physical forcings affecting suspended sediments dynamics in two macrotidal, highlyturbid estuaries. Estuar. Coast. Shelf Sci. 198, 529-541. doi: 10.1016/j.ecss.2017. 02.017

Kemp, W. M., Testa, J. M., Conley, D. J., Gilbert, D., and Hagy, J. D. (2009). Temporal responses of coastal hypoxia to nutrient loading and physical controls. Biogeosciences 6, 2985-3008. doi: 10.5194/bg-6-2985-2009
Kromkamp, J., and Peene, J. (1995). Possibility of net phytoplankton primary production in the turbid Schelde estuary (SW Netherlands). Mar. Ecol. Prog. Ser. 121, 249-259. doi: 10.3354/meps121249

Lajaunie-Salla, K., Sottolichio, A., Schmidt, S., Litrico, X., Binet, G., and Abril, G. (2018). Future intensification of summer hypoxia in the tidal garonne river (SW France) simulated by a coupled hydro-sedimentary-biogeochemical model. Environ. Sci. Poll. Res. 25, 31957-31970. doi: 10.1007/s11356-0183035-6

Lanoux, A., Etcheber, H., Schmidt, S., Sottolichio, A., Chabaud, G., Richard, M., et al. (2013). Factors contributing to hypoxia in a highly turbid, macrotidal estuary (the Gironde, France). Environ. Sci. Process. Impacts 15, 585-595. doi: $10.1039 / \mathrm{c} 2 \mathrm{em} 30874 \mathrm{f}$

Rabalais, N., Diaz, R. J., Levin, L. A., Turner, R. E., Gilbert, D., and Zhang, J. (2010). Dynamics and distribution of natural and human-caused hypoxia. Biogeosciences 7, 585-619. doi: 10.5194/bg-7-585-2010

Schmidt, S. (2019). Longitudinal Distribution of Salinity, Temperature, Turbidity and Dissolved Oxygen of Surface Waters in the Loire and Gironde Estuaries. France: SEANOE, doi: 10.17882/60629

Schmidt, S., Bernard, C., Escalier, J. M., Etcheber, H., and Lamouroux, M. (2017). Assessing and managing the risks of hypoxia in transitional waters: a case study in the tidal garonne river (South-West France). Environ. Sci. Pollut. Res. 24, 3251-3259. doi: 10.1007/s11356-016-7654-5

Toublanc, F., Brenon, I., and Coulombier, T. (2016). Formation and structure of the turbidity maximum in the macrotidal charente estuary (France): influence of fluvial and tidal forcing. Estuar. Coast. Shelf Sci. 169, 1-14. doi: 10.1016/j.ecss. 2015.11.019

Trolle, D., Nielsen, A., Andersen, H. E., Thodsena, H., Olesen, J. E., Børgesen, C. D., et al. (2019). Effects of changes in land use and climate on aquatic ecosystems: coupling of models and decomposition of uncertainties. Sci. Total Environ. 657, 627-633. doi: 10.1016/j.scitotenv.2018.12.055

Warwick, R. M., Tweedley, J. R., and Potter, I. C. (2018). Microtidal estuaries warrant special management measures that recognize their critical vulnerability to pollution and climate change. Mar. Pollut. Bull. 135, 41-46. doi: 10.1016/j. marpolbul.2018.06.062

Woodland, R. J., Secor, D. H., and Niklitschek, E. J. (2009). Past and future habitat suitability for the hudson river population of shortnose sturgeon: a bioenergetic approach to modeling habitat suitability for an endangered species. Am. Fish. Soc. Symp. 69, 589-604.

Xing, Y., Ai, C., and Jin, S. (2013). A three-dimensional hydrodynamic and salinity transport model of estuarine circulation with an application to a macrotidal estuary. Appl. Ocean Res. 39, 53-71. doi: 10.1016/j.apor.2012. 10.003

Zhang, P., Pang, Y., Pan, H., Shi, C., Huang, Y., and Wang, J. (2015). Factors contributing to hypoxia in the minjiang river estuary. Int. J. Environ. Res. Public Health 12, 9357-9374. doi: 10.3390/ijerph120809357

Conflict of Interest Statement: The authors declare that the research was conducted in the absence of any commercial or financial relationships that could be construed as a potential conflict of interest.

Copyright (c) 2019 Schmidt, Diallo, Derriennic, Fallou and Lepage. This is an openaccess article distributed under the terms of the Creative Commons Attribution License (CC BY). The use, distribution or reproduction in other forums is permitted, provided the original author(s) and the copyright owner(s) are credited and that the original publication in this journal is cited, in accordance with accepted academic practice. No use, distribution or reproduction is permitted which does not comply with these terms. 